Delay and secrecy: Does industry sponsorship jeopardize disclosure of academic research?

Dirk Czarnitzki, Christophe Grimpe and Andrew A. Toole

DEPARTMENT OF MANAGERIAL ECONOMICS, STRATEGY AND INNOVATION (MSI) 


\section{Non-technical summary}

It has almost become conventional wisdom that the viability of modern open science norms and practices depends on public disclosure of new knowledge, methods, and materials. At the same time, long-run trends suggest a broad shift is taking place in the institutional financing structure that supports academic research. According to data compiled by the OECD, industry sources are financing a growing share of academic research while "core" public funding is generally shrinking. This ongoing shift from public to private sponsorship is a cause for concern because these sponsorship relationships are fundamentally different. Available evidence suggests that industry financing does not simply replace dwindling public money, but imposes additional restrictions on academic researchers. In particular, industry sponsors frequently limit disclosure of research findings, methods, or materials by delaying or banning public release.

Hence, in this paper we examine the relationship between industry sponsorship and restrictions on disclosure using individual-level data on German academic researchers. Our results show a strong positive relationship between the degree of publication restrictions and the share of industry sponsorship. The percentage of respondents who reported higher secrecy (partial or full) is significantly larger for industry sponsored researchers than it is for researchers with other extramural sponsors, $41 \%$ and $7 \%$ respectively. Holding other factors constant, a $10 \%$ increase in a researcher's share of industry sponsorship increases the probability that he or she will experience publication delay or secrecy by 4.4 percentage points. In this respect, our results shed light on an important challenge facing policymakers. Understanding the trade-off between public and private sponsorship of academic research involves gauging the impact of disclosure restrictions on the quantity, quality, and evolution of academic research to better understand how these restrictions may ultimately influence innovation and economic growth. 


\title{
Delay and secrecy: Does industry sponsorship jeopardize disclosure of academic research?
}

\author{
Dirk Czarnitzki $^{\mathrm{a}, \mathrm{b}, \mathrm{c}}$, Christoph Grimpe ${ }^{\mathrm{d}}$, and Andrew A. Toole ${ }^{\mathrm{c}, \mathrm{e}}$ \\ a) K.U.Leuven, Dept. of Managerial Economics Strategy and Innovation, Leuven (Belgium) \\ b) Centre for R\&D Monitoring (ECOOM) at K.U.Leuven \\ c) Centre for European Economic Research (ZEW), Mannheim (Germany) \\ d) Copenhagen Business School, Copenhagen (Denmark) \\ e) U.S. Department of Agriculture, Economic Research Service, Washington DC (United States)
}

January 2011

\begin{abstract}
The viability of modern open science norms and practices depend on public disclosure of new knowledge, methods, and materials. Aggregate data from the OECD show a broad shift in the institutional financing structure that supports academic research from public to private sponsorship. This paper examines the relationship between industry sponsorship and restrictions on disclosure using individual-level data on German academic researchers. Accounting for selfselection into extramural sponsorship, our evidence strongly supports the perspective that industry sponsorship jeopardizes public disclosure of academic research.
\end{abstract}

Keywords: open science, research funding, industry sponsorship, disclosure, secrecy JEL-Classification: O31; O32; L33

Contact details:

Dirk Czarnitzki, K.U.Leuven, Dept. of Managerial Economics, Strategy and Innovation Naamsestraat 69, 3000 Leuven, Belgium

Phone: +32 16326 906, Fax: +32 16326 732, E-Mail: dirk.czarnitzki@econ.kuleuven.be

Christoph Grimpe, Copenhagen Business School, Dept. of Innovation and Organizational Economics, Kilevej 14A, 2000 Frederiksberg, Denmark

Phone: +45 3815 2530, Fax: +45 3815 2540, E-Mail: christoph@cbs.dk

Andrew A. Toole, USDA, Economic Research Service

1800 M Street NW, Washington DC 20036, USA

Phone: +1 202694 5208, Fax: +1 202694 5776, E-Mail: atoole@ers.usda.gov

Acknowledgements and disclaimer:

Czarnitzki gratefully acknowledges funding from the Flemish Science Foundation (FWO grant: G.0501.11). The views expressed in this article are the authors' and do not necessarily represent the views of the U.S. Department of Agriculture or the Economic Research Service. 


\section{Introduction}

Long-run trends suggest a broad shift is taking place in the institutional financing structure that supports academic research. According to data compiled by the OECD, industry sources are financing a growing share of academic research while "core” public funding is generally shrinking. ${ }^{1}$ This ongoing shift from public to private sponsorship is a cause for concern because these sponsorship relationships are fundamentally different. Available evidence suggests that industry financing does not simply replace dwindling public money, but imposes additional restrictions on academic researchers. In particular, industry sponsors frequently limit disclosure of research findings, methods, or materials by delaying or banning public release (Blumenthal et al. 1996, Cohen et al. 1998, Thursby and Thursby 2007).

Recent economic research highlights why public disclosure of academic research is important. Disclosure permits the "stock of public knowledge" to be cumulative, accessible, and reliable. It limits duplication of research efforts, allows new knowledge to be replicated and verified by professional peers, and permits access and use by other researchers which enhances opportunities for complementary research (Dasgupta and David 1994). In recent work, Murray et al. (2009) found that greater access to ideas and materials in academic research not only increased incentives for direct follow-on research, but led to an increase in the diversity of research by increasing the number of experimental research lines. Mukherjee and Stern (2009), who examined the theoretical conditions supporting "open science” versus "secrecy", stressed that maintaining and growing the stock of public knowledge requires a limit on the private financial returns obtained through secrecy.

${ }^{1}$ OECD data show the share of industry sponsorship has grown in all countries since 1980, although this share is still relatively small. General university funds ("core" funds) as a share of civilian government budget appropriations fell from 26\% in 1995 to 23\% in 2007 (OECD, Main Science and Technology Indicators, 2010). 
This paper examines the relationship between industry sponsorship and restrictions on disclosure using individual-level data on German academic researchers. Germany is an apt setting for examining this relationship. It has a strong tradition of public financial support for academic research and, among advanced economies, Germany experienced the most dramatic growth in its share of industry sponsorship, a 13.4 percentage point increase from 1995 to 2007 (OECD 2010). German academic researchers were surveyed about the degree of disclosure restrictions on publications experienced during sponsored research projects. To examine if industry sponsorship jeopardizes disclosure of academic research, we modeled the degree of restrictiveness (i.e. delay, partial secrecy, and complete secrecy) as a function of the researcher's budget share financed by industry. Using the share of industry sponsorship mirrors the shift in institutional financing highlighted by the OECD data and advances the literature beyond the use of simple indicator variable formulations. Our models also take into account non-industry extramural sponsorship, personal characteristics, research characteristics, institutional affiliations, and scientific fields of study.

Both the descriptive and regression results show a strong positive relationship between the degree of publication restrictions and the share of industry sponsorship. The percentage of respondents who reported higher secrecy (partial or full) is significantly larger for industry sponsored researchers than it is for researchers with other extramural sponsors, $41 \%$ and $7 \%$ respectively. Holding other factors constant, a $10 \%$ increase in a researcher's share of industry sponsorship increases the probability that he or she will experience publication delay or secrecy by 4.4 percentage points, which is a $17.4 \%$ increase in the predicted probability that an "average" researcher will experience publication delay or secrecy. This result is robust to the possibility that researchers self-select into extramural sponsorship and to the possibility that the share of industry sponsorship is endogenous due to unobserved variables. Based on our analysis, the shift from public to private sponsorship 
seen in the OECD aggregate data reflect changes in the microeconomic environment shaping incentives for disclosure by academic researchers. On average, academic researchers are willing to restrict disclosure in exchange for financial support by industry sponsors. Our results shed light on an important challenge facing policymakers. Understanding the trade-off between public and private sponsorship of academic research involves gauging the impact of disclosure restrictions on the quantity, quality, and evolution of academic research to better understand how these restrictions may ultimately influence innovation and economic growth.

The rest of the paper is organized as follows. The next section summarizes the current literature on sponsorship of academic research. The researcher-level data, estimation issues and methods are discussed in section 3. The results and concluding remarks appear in sections 4 and 5, respectively.

\section{Sponsorship of Academic Research}

More than a simple transfer of funds, sponsorship of academic research involves contractual relationships that often specify the nature, ownership, and control rights for research findings, methods, or materials. While these contracts are necessarily "incomplete" due to a number of informational problems, they reflect negotiated outcomes between sponsors and researchers that can have far reaching implications for the organization and conduct of academic research. Historically, as argued by David (2004), sponsorship relationships helped to transform the norms, incentives, and organizational structures of scientific inquiry from a system dominated by secrecy to a modern “open science” system characterized by rapid public disclosure of new knowledge. ${ }^{2}$ Relative to a secrecy system, open science is

${ }^{2}$ Open science is broadly associated with universities and other not-for-profit research institutions that practice the "priority" reward system and support the professional ethos associated with the community of academic scientists as articulated by sociologist Robert K. Merton (see, for instance, Merton 1973, Dasgupta and David 1994, Stephan 1996). David (2004) highlights the norms of "universalism” (open entry and discourse) and "communism” (full and open disclosure) as particularly relevant to openness. 
considered to be an efficient and welfare enhancing system for the production of a cumulative, accessible, and reliable stock of public scientific and technical knowledge (Dasgupta and David 1994, Mukherjee and Stern 2008).

As history suggests, the objectives and institutional reward systems practiced by different sponsors may influence the norms, incentives, and organizational structures of academic research differently. "Public" sponsors such as science-oriented state agencies or private foundations focus on advancing public knowledge. These institutions expect sponsored research to result in new knowledge that is publicly disclosed through various channels including publication. In fact, public support often depends on a satisfactory performance as indicated by a researcher's publication output. Advancing public knowledge through disclosure is consistent with the "priority" reward system and reinforces open science norms and behaviours. In contrast, "private" sponsors such as military-oriented state agencies or private industry focus on extracting rents from new knowledge by restricting public disclosure. ${ }^{3}$ Advocating restrictions on disclosure is likely to have a corrosive effect on open science.

One approach to learning about sponsorship relationships is to ask the sponsors. We found two published studies that surveyed private firms about the characteristics of sponsored research contracts. ${ }^{4}$ Based on survey responses from 210 life science companies, Blumenthal et al. (1996) found evidence of both publication delay and secrecy (nondisclosure) restrictions on information resulting from academic research. For instance, fifty-eight percent of the companies typically required researchers to keep information confidential for

\footnotetext{
${ }^{3}$ Gans et al. (2010) use a theoretical framework to examine the "regimes" of disclosure under private industry sponsorship.

${ }^{4}$ We did not find any studies that systematically analyze the contractual terms of scientific or militaryoriented contracts from state sponsors or private foundations. Cohen at al. (1998) reported that 53 percent of university-industry research centers allowed firms to impose publication delays and 35 percent allowed firms to impose secrecy through the deletion of information before publishing. For a sample of 130 French public labs that have 875 industrial partners, Goddard and Isabelle (2006) reported that 55\% allowed contract provisions to delay publication and 53\% allowed contract provisions to suppress information from publication.
} 
more than six months. Using survey responses from 112 firms engaged in university licensing, Thursby and Thursby (2007) reported that ninety percent of the university contracts included publication delay clauses.

A more direct approach, which is followed in this paper, is to ask academic researchers about any disclosure restrictions they experienced when undertaking extramurally sponsored research. We found six studies that used researcher-level survey data to shed light on the relationship between industry sponsorship and disclosure. In five of these studies, Blumenthal and colleagues described the results of three separate life science faculty surveys conducted between 1985 and 2000 (Blumenthal et al.1986, 1996a,b , 1997, 2006; Campbell et al. 2002). Their findings show that researchers with at least one industry sponsored project are more likely to report industry ownership of research results, pre-publication review, publication delays, and secrecy to protect proprietary information. ${ }^{5}$ Taking a slightly different perspective, Hong and Walsh (2009) ask researchers how "safe" they feel about discussing their current work with non-collaborating colleagues. For their full sample, academic researchers with at least one industry sponsored project were more likely to feel "unsafe” (interpreted as being more secretive).

Our analysis extends this mostly descriptive literature in three ways. First, we expand the scope of evidence by analyzing academic researchers who work outside the United States in a broader set of scientific fields and institutional settings. All of the prior work analyzing how industry sponsorship influences disclosure looked at U.S. researchers working in a handful of scientific fields at American universities. Dasgupta and David (1994) highlighted how alternative institutional settings may influence a researcher's choice about disclosure. Second, to account for heterogeneity in the degree of industry sponsorship, our analysis uses the budget share of industry support instead of a simple indicator variable formulation.

\footnotetext{
${ }^{5}$ Using an industry funding indicator, Walsh et al. (2007) found no relationship between industry funding and compliance with requests for research inputs among biomedical researchers performing genomic and proteomic-related research.
} 
Third, our empirical analysis is the first to address potential self-selection by academic researchers into extramural sponsorship and to use an instrumental variables method to account for unobserved factors.

\section{Data and Methods}

\subsection{Data}

To analyze the relationship between industry sponsorship and disclosure restrictions on publications we used a researcher-level database. In 2008, the Centre for European Economic Research (ZEW) undertook an online survey of German academic researchers. The survey population was defined to include German researchers who held a Ph.D. degree and worked at either a university or a not-for-profit research institution. Information on university affiliated researchers was collected from a register of German professors (“Hochschullehrerverzeichnis”) which excludes universities of applied sciences that focus on teaching. For Germany’s largest not-for-profit research institutions (Fraunhofer Society, Max Planck Society, Helmholtz Association, Leibniz Association), information on affiliated researchers was collected using internet searches. ${ }^{6}$

In total, the survey led to 1,404 valid responses. After dropping observations with missing values in the variables of interest for this study, we end up with a final sample of 1,060 observations.

The dependent variable is drawn from a question that asked respondents to indicate the degree of disclosure restrictions on publications resulting from extramural sponsorship. It

\footnotetext{
${ }^{6}$ Major research institutions in Germany are not only universities but other public research institutions that have many branches in a variety of different scientific disciplines. For instance, the Fraunhofer Society has 59 institutes in Germany with about 17,000 employees, the Max-Planck Society has 76 institutes with about 12,000 employees. The Leibniz Association employs 16,100 people in 86 research centres. The Helmholtz Association has about 30,000 employees in 16 research centres. University professors are frequently heads of research groups at these institutions, i.e. they have a university affiliation but are typically on leave full-time when working with the research institutes.
} 
asked: "Has the funding of your research by public or private extramural sponsors resulted in: (a) a complete ban on publishing research; (b) a partial ban on publishing research; or (c) a delay in publishing research due to contractual agreements.” Respondents could check one of three boxes for each outcome indicating “yes”, “no”, or "not relevant”. For the empirical analysis, we coded two alternative dependent variables based on this question. The first is a dummy variable indicating the respondent experienced any delay or secrecy due to extramural funding. This binary variable takes the value of one if the respondent indicated "yes" to any of the outcomes. The second is an ordered variable with four categories indicating higher levels of secrecy: no delay or ban, delay of publications, partial ban on publication, and total ban on publication.

The main explanatory variable in the analysis is the share of the researcher's extramural budget funded by private industry sponsors. This variable was constructed using two survey questions. The first question asked the researcher to report his or her total extramural budget over the five year period from 2002 to 2006. Conditional on having extramural funding, the second question asked the researcher to provide the source (as a percentage) of his or her total extramural budget over the five year period. The share of industry sponsorship is the proportion of researcher's budget funded by private sector organizations.

We used a number of other variables collected through the survey as controls or instrumental variables in the empirical analysis. These variables are grouped into four categories: research characteristics, personal characteristics, institutional affiliations, and scientific fields of study. Research characteristics relate to the individual's position at the research institution, his or her total extramural funding, publications, patent applications, and his or her opinion about the peer review process. Personal characteristics include the individual's age and gender, and whether he or she is tenured. Institutional affiliations cover 
universities, the four major not-for-profit public research institutions mentioned above, and a catchall group for all other affiliations. Further, the researchers were grouped into four broad scientific fields specified as life sciences, natural sciences, engineering, and social sciences.

\subsection{Methods}

In the ideal case, we would use an experimental design to identify the causal effect of industry sponsorship on disclosure choices by academic researchers. For instance, one might randomly assign industry sponsorship to academic researchers, allow for negotiation and research, and observe changes in disclosure. This type of experiment would eliminate any bias due to self-section by academic researchers into funding. Our survey data, however, were not collected using a randomized experimental design. With our data, we do not observe the choice by an academic researcher to seek or accept extramural sponsorship and this suggests simple Probit and ordered Probit estimators could be biased by self-section. Academic researchers who received extramural funding are probably different from those who did not receive funding. For instance, researchers who are less concerned about disclosure or perform more "applied” research may be more willing to accept extramural sponsorship that imposes disclosure restrictions. ${ }^{7}$ This would lead to an upward bias. To address this possibility, our empirical analysis includes Probit and ordered Probit models accounting for selection into funding. In these models, the academic researcher's age and gender serve as exclusion restrictions that predict the receipt of extramural funding, but do not influence the researcher's disclosure outcome. These exclusion restrictions are supported

${ }^{7}$ Define $\mathrm{Y}_{0 \mathrm{i}}$ as the non-disclosure (or secrecy) outcome for academic researcher $\mathrm{i}$ in the state of not receiving extramural funding and define $D_{i}$ as the funding indicator: $D_{i}=1$ when funded and $D_{i}=0$ when not funded. Selection bias is positive when those who actually received funding value non-disclosure more in the unfunded state: $E\left[Y_{0 i} \mid D_{i}=1\right]-E\left[Y_{0 i} \mid D_{i}=0>0\right.$. 
statistically. Neither gender nor age significantly influence disclosure restrictions on publications once other factors are held constant. ${ }^{8}$

While our survey instrument provides fairly rich researcher-level information, we do not observe the researcher's perception of scientific competition within his or her field. Current studies find that greater scientific competition is associated with greater secrecy (Hong and Walsh 2009, Haeussler 2011). Relevant for this analysis, however, is the relationship between scientific competition and extramural sponsorship. Scientific competition may either increase or decrease the attractiveness of extramural sponsorship. On the one hand, researchers feeling intense competition for priority may be less willing to accept third party disclosure restrictions. On the other hand, extramural sponsorship may provide financial resources that help the researcher get work done faster. The direction of potential bias could go either way. In our analysis, we included scientific field dummy variables to capture differences in the level of scientific competition across fields.

Standard descriptive statistics for the variables used in the regression models are reported in Table 1.

\footnotetext{
${ }^{8}$ In addition to being statistically valid, other research on academic sharing behaviors and attitudes toward cooperation with private firms do not find gender to be significant (Haeussler 2011, Audretsch et al. 2010). Haeussler (2011) finds that a researcher's age decreases the percent of requested information that is shared.
} 
Table 1: Regression descriptive statistics

\begin{tabular}{|c|c|c|c|c|}
\hline \multicolumn{5}{|c|}{ Data used in selection equation $(\mathrm{N}=1,060)$} \\
\hline Dependent variable & Mean & Std. Dev. & Min & Max \\
\hline Any extramural sponsorship & 0.808 & 0.394 & 0 & 1 \\
\hline \multicolumn{5}{|l|}{ Research Characteristics } \\
\hline Research group leader & 0.722 & 0.448 & 0 & 1 \\
\hline Journal publications & 21.420 & 26.920 & 0 & 178 \\
\hline Patent applications & 0.749 & 2.101 & 0 & 24 \\
\hline \multicolumn{5}{|l|}{ Personal Characteristics } \\
\hline Tenure & 0.842 & 0.364 & 0 & 1 \\
\hline Female & 0.148 & 0.355 & 0 & 1 \\
\hline Age & 49.531 & 8.225 & 28 & 74 \\
\hline \multicolumn{5}{|l|}{ Institutions } \\
\hline University & 0.586 & 0.493 & 0 & 1 \\
\hline Fraunhofer Society & 0.051 & 0.220 & 0 & 1 \\
\hline Max Planck Society & 0.085 & 0.279 & 0 & 1 \\
\hline Helmholtz Association & 0.165 & 0.371 & 0 & 1 \\
\hline Leibniz Association & 0.070 & 0.255 & 0 & 1 \\
\hline Other Institution & 0.087 & 0.282 & 0 & 1 \\
\hline \multicolumn{5}{|l|}{ Science Fields } \\
\hline Life sciences & 0.305 & 0.461 & 0 & 1 \\
\hline Natural sciences & 0.292 & 0.455 & 0 & 1 \\
\hline Engineering & 0.192 & 0.394 & 0 & 1 \\
\hline Social sciences & 0.211 & 0.408 & 0 & 1 \\
\hline \multicolumn{5}{|c|}{ Data used in withholding regressions $(\mathrm{N}=856)$} \\
\hline Dependent variable & Mean & Std. Dev. & Min & Max \\
\hline Delay or ban (ordered variable) & 0.560 & 0.957 & 0 & 3 \\
\hline Delay or ban (dummy variable) & 0.289 & 0.453 & 0 & 1 \\
\hline \multicolumn{5}{|l|}{ Research Characteristics } \\
\hline Industry share & 0.111 & 0.212 & 0 & 1 \\
\hline Total budget (million Euro) & 1.695 & 3.738 & 0.001 & 75 \\
\hline Research group leader & 0.792 & 0.406 & 0 & 1 \\
\hline Journal publications & 23.557 & 28.125 & 0 & 176 \\
\hline Patent applications & 0.836 & 2.215 & 0 & 24 \\
\hline \multicolumn{5}{|l|}{ Personal Characteristics } \\
\hline Tenure & 0.864 & 0.342 & 0 & 1 \\
\hline \multicolumn{5}{|l|}{ Institutions } \\
\hline University & 0.613 & 0.487 & 0 & 1 \\
\hline Fraunhofer Society & 0.051 & 0.221 & 0 & 1 \\
\hline Max Planck Society & 0.074 & 0.261 & 0 & 1 \\
\hline Helmholtz Association & 0.152 & 0.359 & 0 & 1 \\
\hline Leibniz Association & 0.065 & 0.247 & 0 & 1 \\
\hline Other Institution & 0.084 & 0.278 & 0 & 1 \\
\hline \multicolumn{5}{|l|}{ Science Fields } \\
\hline Life sciences & 0.299 & 0.458 & 0 & 1 \\
\hline Natural sciences & 0.292 & 0.455 & 0 & 1 \\
\hline Engineering & 0.210 & 0.408 & 0 & 1 \\
\hline Social sciences & 0.199 & 0.399 & 0 & 1 \\
\hline
\end{tabular}




\section{$4 \quad$ Results}

\subsection{Main results}

Table 2 presents descriptive statistics for the full sample of German researchers and for subsamples broken out by extramural funding. Most respondents indicated some extramural sponsorship (81\%) with nearly one third having industry sponsorship. On average, researchers with industry sponsorship had larger research budgets, published more in journals, and applied for more patents. Personal characteristics of researchers were similar except for a significant drop in the proportion of females for the group of industry sponsored researchers. A greater proportion of university and Fraunhofer affiliated researchers reported industry sponsorship while the proportion of industry sponsored researchers is quite small for affiliates of the Max Planck Society, which is strongly oriented toward basic research. Among the science fields, industry sponsorship was greatest in engineering.

Next we examined the average values of the covariates for different levels of restriction (no delay or secrecy, delay, partial or full secrecy) grouped by extramural, industry, and non-industry sponsorship as shown in Table 3. Out of the 341 respondents that reported some industry sponsorship, 50\% reported no delay or secrecy on publications, $9 \%$ reported a delay, and $41 \%$ reported a partial or full secrecy on publications. The percentage of respondents who reported the higher secrecy (partial or full) is significantly (at the $1 \%$ level) larger for industry sponsored researchers than it is for researchers with non-industry sponsorship, $41 \%$ and $7 \%$ respectively. The positive association between industry share and level of secrecy is already evident in Table 3. As one looks across the columns from no restrictions (no delay/ban) to higher secrecy (partial/full), researchers reported larger industry sponsorship shares. Higher secrecy was reported more frequently by researchers affiliated with applied public research organizations such as the Fraunhofer Society and Helmholtz 
Association. Among the science fields, the proportion who reported partial or total secrecy on publishing is greatest in engineering.

Table 2: Sample averages for all covariates by extramural sponsorship

\begin{tabular}{lcccc}
\hline & $\begin{array}{c}\text { All } \\
\text { Respondents }\end{array}$ & $\begin{array}{c}\text { No External } \\
\text { Funding }\end{array}$ & $\begin{array}{c}\text { Any External } \\
\text { Funding }\end{array}$ & $\begin{array}{c}\text { Industry } \\
\text { Funding }\end{array}$ \\
\hline Total Observations (\% of all obs) & 1060 & $204(19 \%)$ & $856(81 \%)$ & $341(32 \%)$ \\
Report a delay or ban of research & & - & 0.289 & 0.504 \\
Research Characteristics & & & & \\
$\quad$ Industry share & - & - & 0.111 & 0.279 \\
$\quad$ Total budget (million Euro) & - & - & 1.695 & 2.163 \\
$\quad$ Research group leader & 0.722 & 0.426 & 0.792 & 0.862 \\
Journal publications & 21.42 & 12.451 & 23.557 & 26.595 \\
$\quad$ Patent applications & 0.749 & 0.382 & 0.836 & 1.537 \\
Personal Characteristics & & & & \\
Tenure & 0.842 & 0.75 & 0.864 & 0.918 \\
Female & 0.148 & 0.176 & 0.141 & 0.088 \\
Age & 49.5 & 50.4 & 49.3 & 50.2 \\
Institutions & & & & \\
University & 0.586 & 0.471 & 0.613 & 0.642 \\
Fraunhofer Society & 0.051 & 0.049 & 0.051 & 0.117 \\
Max Planck Society & 0.085 & 0.132 & 0.074 & 0.035 \\
Helmholtz Association & 0.165 & 0.221 & 0.152 & 0.106 \\
Leibniz Association & 0.07 & 0.088 & 0.065 & 0.053 \\
Other Institution & 0.087 & 0.098 & 0.084 & 0.073 \\
Science Fields & & & & \\
Life sciences & 0.305 & 0.328 & 0.299 & 0.279 \\
Natural sciences & 0.292 & 0.294 & 0.292 & 0.214 \\
Engineering & 0.192 & 0.113 & 0.21 & 0.378 \\
Social sciences & 0.211 & 0.265 & 0.199 & 0.129 \\
\hline
\end{tabular}


Table 3: Sample averages by level of publication restriction and type of extramural sponsorship

\begin{tabular}{|c|c|c|c|c|c|c|c|c|c|}
\hline & \multicolumn{3}{|c|}{ Any External Funding ( $\mathrm{N}=856)$} & \multicolumn{3}{|c|}{ Industry Funding $(\mathrm{N}=341)$} & \multicolumn{3}{|c|}{ Non-Industry Funding ( $\mathrm{N}=515)$} \\
\hline & $\begin{array}{c}\text { No Delay or } \\
\text { Ban }\end{array}$ & Delay & $\begin{array}{c}\text { Partial or } \\
\text { Full Ban }\end{array}$ & $\begin{array}{c}\text { No Delay or } \\
\text { Ban }\end{array}$ & Delay & $\begin{array}{c}\text { Partial or } \\
\text { Full Ban }\end{array}$ & $\begin{array}{c}\text { No Delay or } \\
\text { Ban }\end{array}$ & Delay & $\begin{array}{c}\text { Partial or } \\
\text { Full Ban }\end{array}$ \\
\hline Total Observations (\%) & 609 (71\%) & $69(8 \%)$ & 178 (21\%) & $169(50 \%)$ & $32(9 \%)$ & $140(41 \%)$ & $440(85 \%)$ & $37(7 \%)$ & $38(7 \%)$ \\
\hline \multicolumn{10}{|l|}{ Research Characteristics } \\
\hline Industry share & 0.067 & 0.116 & 0.26 & 0.241 & 0.25 & 0.331 & - & - & - \\
\hline Total budget (million Euro) & 1.517 & 1.633 & 2.327 & 1.993 & 1.938 & 2.42 & 1.334 & 1.370 & 1.982 \\
\hline Research group leader & 0.788 & 0.841 & 0.787 & 0.882 & 0.938 & 0.821 & 0.752 & 0.757 & 0.658 \\
\hline Journal publications & 25.504 & 27.507 & 15.365 & 34.64 & 34.906 & 14.979 & 21.993 & 21.108 & 16.789 \\
\hline Patent applications & 0.473 & 1.551 & 1.803 & 0.941 & 2.031 & 2.143 & 0.293 & 1.135 & 0.553 \\
\hline \multicolumn{10}{|l|}{ Personal Characteristics } \\
\hline Tenure & 0.856 & 0.884 & 0.888 & 0.911 & 0.969 & 0.914 & 0.834 & 0.811 & 0.789 \\
\hline Female & 0.151 & 0.159 & 0.101 & 0.089 & 0.1875 & 0.064 & 0.175 & 0.135 & 0.237 \\
\hline Age & 49.2 & 50 & 49.2 & 50.4 & 51.2 & 49.7 & 48.9 & 48.9 & 47.3 \\
\hline \multicolumn{10}{|l|}{ Institutions } \\
\hline University & 0.65 & 0.609 & 0.489 & 0.769 & 0.688 & 0.479 & 0.605 & 0.541 & 0.526 \\
\hline Fraunhofer Society & 0.016 & 0.058 & 0.169 & 0.041 & 0.094 & 0.214 & 0.007 & 0.027 & 0 \\
\hline Max Planck Society & 0.094 & 0.029 & 0.022 & 0.053 & 0.031 & 0.014 & 0.109 & 0.027 & 0.053 \\
\hline Helmholtz Association & 0.146 & 0.13 & 0.180 & 0.065 & 0.063 & 0.164 & 0.177 & 0.189 & 0.237 \\
\hline Leibniz Association & 0.062 & 0.072 & 0.073 & 0.036 & 0.094 & 0.064 & 0.073 & 0.054 & 0.105 \\
\hline Other Institution & 0.076 & 0.116 & 0.101 & 0.059 & 0.063 & 0.093 & 0.082 & 0.162 & 0.132 \\
\hline \multicolumn{10}{|l|}{ Science Fields } \\
\hline Life sciences & 0.332 & 0.333 & 0.174 & 0.385 & 0.344 & 0.136 & 0.311 & 0.324 & 0.316 \\
\hline Natural sciences & 0.322 & 0.304 & 0.185 & 0.213 & 0.25 & 0.207 & 0.364 & 0.351 & 0.105 \\
\hline Engineering & 0.13 & 0.116 & 0.522 & 0.266 & 0.219 & 0.55 & 0.077 & 0.027 & 0.421 \\
\hline Social sciences & 0.217 & 0.246 & 0.118 & 0.136 & 0.397 & 0.107 & 0.248 & 0.297 & 0.158 \\
\hline
\end{tabular}


Our regression analysis begins by considering a binary outcome that indicates whether a researcher who was supported by an extramural sponsor experienced any type of publication delay or secrecy. Model A in Table 4 shows the results of a basic Probit regression that ignores selection into extramural funding. Model B controls for self-selection into extramural funding (see e.g. Wooldridge, 2002: 570, for technical details). Holding the size of the researcher's extramural budget constant (as well as other factors), the share of industry sponsorship significantly increases the probability of publication delay or secrecy in both models. The correlation across equations in Model B, reported at the bottom of the table as rho, is negative and highly significant which indicates self-selection into extramural funding is important. Controlling for self-selection, the coefficient estimate on industry share is $18 \%$ smaller, but still highly significant. From Model B, a 10\% increase in the industry share increases the probability that he or she will experience publication delay or secrecy by 4.4 percentage points. At the mean values of the covariates, the predicted probability of experiencing delay or secrecy increases by $17.4 \%$ from 0.253 to 0.297 . This result supports concerns that industry sponsorship undermines the norms and practices of open science and jeopardizes the cumulative nature and reliability of public scientific and technical knowledge. A larger total extramural budget is also associated with greater publication restrictions.

It is also informative to examine how other covariates influence publication delay or secrecy when the effects of industry share and extramural budget size are held constant. From Model B, research characteristics and institutional affiliations matter even after controlling for selection. A researcher who is a group leader or had more journal publications is less likely to experience delay or secrecy restrictions. Group leaders and productive researchers are likely to value disclosure more and possess more bargaining power with extramural sponsors. This is 
consistent with Audretsch et al. (2010) who found group leadership to be associated with more cooperation experience and planned cooperation with private companies.

Researchers who submit more patent applications are more likely to restrict publications either through delay or secrecy. Relative to university researchers, those affiliated with the Fraunhofer Society, Helmholtz and Leibniz Associations are more likely to experience publication delay or secrecy. Given our data, we cannot distinguish between an institutional "management" effect, reflecting the strength of the technology transfer capabilities at these institutions, versus an institutional "focus" effect, reflecting the relatively applied orientation of research at these institutions. As described in Section 2, most of the literature has focused on researchers in the life sciences and its subfields. Looking at Model A, our results indicate that the life sciences are not significantly more likely to experience delays or secrecy on publications relative to the base group of social scientists. Only engineering researchers are more likely to experience these publication restrictions. Interestingly, after controlling for selection into extramural sponsorship in Model B, engineering researchers are no longer significantly different from social scientists. 
Table 4: Probit of Withholding Research (binary outcome)

\begin{tabular}{|c|c|c|c|}
\hline \multirow[b]{2}{*}{ Variable } & \multirow{2}{*}{$\begin{array}{c}\text { Model A } \\
\text { Probit (no selection) }\end{array}$} & \multicolumn{2}{|c|}{ Model B } \\
\hline & & $\begin{array}{l}\text { Probit with Selection } \\
\text { Second stage }\end{array}$ & $\begin{array}{l}\text { Probit with Selection } \\
\text { First stage }\end{array}$ \\
\hline \multirow[t]{2}{*}{ Industry share } & $1.427 * * *$ & $1.168 * * *$ & \\
\hline & $(0.235)$ & $(0.210)$ & \\
\hline \multirow[t]{2}{*}{ Total external funding } & $0.152 * * *$ & $0.111^{* * *}$ & \\
\hline & (0.039) & $(0.033)$ & \\
\hline \multirow[t]{2}{*}{ Female } & & & 0.011 \\
\hline & & & $(0.116)$ \\
\hline \multirow[t]{2}{*}{ Age } & & & $0.119 * *$ \\
\hline & & & $(0.053)$ \\
\hline \multirow[t]{2}{*}{ Age-squared } & & & $-0.001 * * *$ \\
\hline & & & $(0.0005)$ \\
\hline \multirow[t]{2}{*}{ Research group leader } & 0.077 & $-0.352 * * *$ & $0.736 * * *$ \\
\hline & $(0.137)$ & $(0.127)$ & $(0.106)$ \\
\hline \multirow[t]{2}{*}{ Tenure } & -0.036 & -0.091 & 0.209 \\
\hline & $(0.153)$ & $(0.126)$ & $(0.148)$ \\
\hline \multirow[t]{2}{*}{ Journal publications } & $-0.006 * * *$ & $-0.007 * * *$ & $0.007 * * *$ \\
\hline & $(0.002)$ & $(0.002)$ & $(0.003)$ \\
\hline \multirow[t]{2}{*}{ Patent applications } & $0.098 * * *$ & $0.090 * * *$ & $0.057^{*}$ \\
\hline & $(0.023)$ & $(0.022)$ & $(0.031)$ \\
\hline \multirow[t]{2}{*}{ Fraunhofer Society } & $0.595^{* *}$ & $0.542^{* *}$ & -0.284 \\
\hline & $(0.247)$ & $(0.224)$ & $(0.233)$ \\
\hline \multirow[t]{2}{*}{ Max Planck Society } & -0.380 & -0.089 & $-0.334 * *$ \\
\hline & $(0.245)$ & $(0.202)$ & $(0.169)$ \\
\hline \multirow[t]{2}{*}{ Helmholtz Association } & 0.221 & $0.238 *$ & $-0.236 *$ \\
\hline & $(0.151)$ & $(0.131)$ & $(0.140)$ \\
\hline \multirow{2}{*}{ Leibniz Association } & $0.423 * *$ & $0.368 * *$ & -0.201 \\
\hline & $(0.200)$ & $(0.173)$ & $(0.185)$ \\
\hline \multirow[t]{2}{*}{ Other institution } & $0.301 *$ & 0.227 & -0.006 \\
\hline & $(0.177)$ & $(0.157)$ & $(0.173)$ \\
\hline \multirow[t]{2}{*}{ Life sciences } & -0.175 & -0.130 & -0.038 \\
\hline & $(0.155)$ & $(0.131)$ & $(0.139)$ \\
\hline \multirow[t]{2}{*}{ Natural sciences } & -0.158 & -0.201 & 0.146 \\
\hline & $(0.162)$ & $(0.137)$ & $(0.144)$ \\
\hline \multirow[t]{2}{*}{ Engineering } & $0.390 * *$ & 0.181 & $0.448 * * *$ \\
\hline & $(0.161)$ & $(0.144)$ & $(0.164)$ \\
\hline \multirow[t]{2}{*}{ Intercept } & $-0.795 * * *$ & 0.042 & $-2.354 *$ \\
\hline & $(0.206)$ & $(0.190)$ & $(1.284)$ \\
\hline Log-Likelihood & -415.788 & \multicolumn{2}{|c|}{-854.607} \\
\hline Equation corr (rho) & - & \multicolumn{2}{|c|}{$-0.916^{* * *}$} \\
\hline \# Observations & 856 & \multicolumn{2}{|c|}{1060} \\
\hline
\end{tabular}


Given the structure of the survey question, it is perhaps more natural to specify an ordered dependent variable with four categories (no delay or secrecy, delay of publications, partial secrecy on publication, and total secrecy on publication) indicating increasing levels of secrecy. Model A in Table 5 reports the ordered Probit results without accounting for selection. The signs and statistical significance of the explanatory variables are nearly identical to those presented in Table 4 Model A. When self-selection is taken into account (see Miranda and Rabe-Hesketh, 2006, for econometric details of the ordered Probit model with selection), as shown in Model B of Table 5, the results from the binary Probit analysis continue to hold. Once again, controlling for self-selection reduces the coefficient estimate on industry share, but it remains highly significant. 
Table 5: Ordered Probit of Withholding Research

\begin{tabular}{|c|c|c|c|}
\hline \multirow[b]{2}{*}{ Variable } & \multirow{2}{*}{$\begin{array}{l}\text { Model A } \\
\text { Ordered Probit (no } \\
\text { selection) }\end{array}$} & \multicolumn{2}{|c|}{ Model B } \\
\hline & & $\begin{array}{c}\text { Ordered Probit with } \\
\text { Selection Second stage }\end{array}$ & $\begin{array}{l}\text { Ordered Probit with } \\
\text { Selection First stage }\end{array}$ \\
\hline \multirow[t]{2}{*}{ Industry share } & $1.567 * * *$ & $1.342 * * *$ & \\
\hline & $(0.209)$ & $(0.189)$ & \\
\hline \multirow[t]{2}{*}{ Total external funding } & $0.153 * * *$ & $0.129 * * *$ & \\
\hline & $(0.037)$ & $(0.030)$ & \\
\hline \multirow[t]{2}{*}{ Female } & & & 0.006 \\
\hline & & & $(0.118)$ \\
\hline \multirow[t]{2}{*}{ Age } & & & $0.134 * *$ \\
\hline & & & $(0.054)$ \\
\hline \multirow[t]{2}{*}{ Age-squared } & & & $-0.002 * * *$ \\
\hline & & & $(0.0005)$ \\
\hline \multirow[t]{2}{*}{ Research group leader } & 0.030 & $-0.348 * * *$ & $0.718^{* * *}$ \\
\hline & $(0.127)$ & $(0.126)$ & $(0.107)$ \\
\hline \multirow[t]{2}{*}{ Tenure } & -0.069 & -0.126 & 0.205 \\
\hline & $(0.144)$ & $(0.125)$ & $(0.147)$ \\
\hline \multirow[t]{2}{*}{ Journal publications } & $-0.006 * * *$ & $-0.007 * * *$ & $0.008 * * *$ \\
\hline & $(0.002)$ & $(0.002)$ & $(0.003)$ \\
\hline \multirow[t]{2}{*}{ Patent applications } & $0.065 * * *$ & $0.053 * * *$ & 0.043 \\
\hline & $(0.019)$ & $(0.018)$ & $(0.032)$ \\
\hline \multirow[t]{2}{*}{ Fraunhofer Society } & $0.678 * * *$ & $0.589 * * *$ & -0.273 \\
\hline & $(0.202)$ & $(0.191)$ & $(0.230)$ \\
\hline \multirow[t]{2}{*}{ Max Planck Society } & -0.380 & -0.147 & $-0.354 * *$ \\
\hline & $(0.239)$ & $(0.205)$ & $(0.169)$ \\
\hline \multirow[t]{2}{*}{ Helmholtz Association } & $0.251 *$ & $0.261 * *$ & $-0.264^{*}$ \\
\hline & $(0.140)$ & $(0.126)$ & $(0.141)$ \\
\hline \multirow[t]{2}{*}{ Leibniz Association } & $0.393 * *$ & $0.350 * *$ & -0.221 \\
\hline & $(0.186)$ & $(0.168)$ & $(0.186)$ \\
\hline \multirow[t]{2}{*}{ Other institution } & $0.287 *$ & 0.210 & -0.051 \\
\hline & $(0.164)$ & $(0.151)$ & $(0.171)$ \\
\hline \multirow[t]{2}{*}{ Life sciences } & -0.131 & -0.103 & -0.034 \\
\hline & $(0.147)$ & $(0.130)$ & $(0.138)$ \\
\hline \multirow[t]{2}{*}{ Natural sciences } & -0.169 & -0.209 & 0.154 \\
\hline & $(0.154)$ & $(0.136)$ & $(0.144)$ \\
\hline \multirow[t]{2}{*}{ Engineering } & $0.538 * * *$ & 0.305 & $0.482 * * *$ \\
\hline & $(0.149)$ & $(0.143)$ & $(0.163)$ \\
\hline \multirow[t]{2}{*}{ Intercept } & & & $-2.665 * *$ \\
\hline & & & $(1.311)$ \\
\hline Log-Likelihood & -642.906 & \multicolumn{2}{|c|}{$-1,082.116$} \\
\hline Equation corr (rho) & - & \multicolumn{2}{|c|}{$-0.834^{* * *}$} \\
\hline \# Observations & 856 & \multicolumn{2}{|c|}{1060} \\
\hline
\end{tabular}




\subsection{Robustness test}

As a further check on the robustness of our main results, we implemented an instrumental variables (IV) approach to account for any endogeneity of industry budget share using an IV Probit model. A valid IV for industry share must be relevant (highly correlated with industry share) and exogenous (independent of unobserved factors influencing the degree of disclosure restrictions on publications). One survey question asked respondents "How do you evaluate the transparency of the referees' decisions regarding your proposal to the $6^{\text {th }}$ European Union Framework program?” Respondents had five choices on a Likert scale ranging from 1 for “very low" to 5 for "very high". This question provides a relevant IV because those researchers who indicated a poor opinion of the EU proposal review process are more likely to consider industry as an alternative extramural sponsor. At the same time, a researcher's opinion about referee reports is arguably independent of factors that influence his or her choice about disclosure. As a second IV, we used the researcher's gender. These IVs were correlated with industry share in the first stage regression with an F-statistic of 5.3 and passed the over-identification test for exogeneity.

The models used fewer observations (542) than the models reported above because responses about the refereeing outcomes were conditional on having applied to the $6^{\text {th }}$ EU Framework program. The first regression reported in Table 6 is a standard binary Probit. The results are quite similar to earlier results except for the science fields. Researchers in the natural sciences are now significantly less likely to report publication restrictions than the base group of social scientists and engineers are no longer significantly different. When an IV Probit method is used as shown in Model B, the coefficient on industry share remains positive and significant. At the same time most of the research characteristics and institutional affiliations are no longer 
significantly related to experiencing publication restrictions. This suggests the effect of industry sponsorship was partially absorbed by research characteristics and institutional affiliation covariates in earlier models. The IV Probit model also reveals more heterogeneity across science fields with researchers in both life sciences and natural sciences being significantly less likely to experience publication restrictions relative to social scientists. 
Table 6: Probit of Withholding Research (binary outcome, all sponsors)

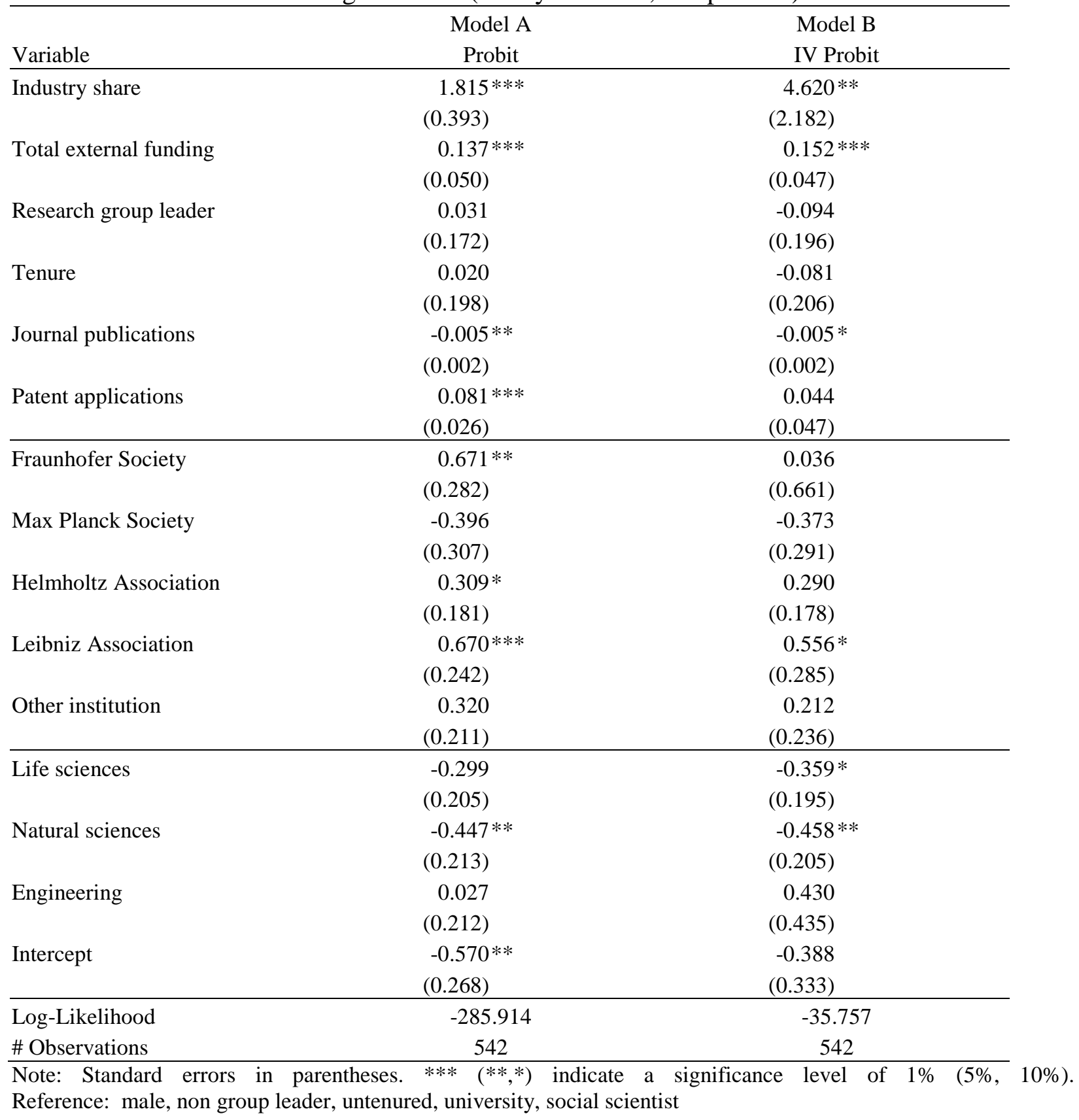

\section{Conclusion}

Using data obtained from individual academic researchers, our evidence strongly supports the perspective that industry sponsorship jeopardizes public disclosure of academic research. Firms expect proprietary benefits from their sponsorship relationships and realizing these benefits often 
requires disclosure restrictions that academic researchers would not otherwise impose. Academic researchers who accepted industry sponsorship reported significantly more disclosure delays and greater secrecy. Importantly, both the descriptive statistics and the regression models indicate these delay and secrecy outcomes increase as the share of industry sponsorship grows. While we cannot unequivocally state that this association is causal, our empirical analysis offered significant advances in this direction. Selection models accounted for self-selection by academic researchers into extramural research funding and IV regression methods addressed concerns about confounding omitted characteristics or potential measurement error.

Our microeconomic evidence provides a lens for interpreting the on-going aggregate shift in institutional financing that supports academic research. As revealed in Figure 1, country-level OECD data show the share of industry sponsorship is generally rising, although not universally or monotonically. Among OECD countries, Germany has the largest share of industry sponsorship, about 25\% in 2007. Our researcher-level evidence from Germany suggests the aggregate shift does not simply represent the substitution of private money for public, but involves a real change in when or if academic research findings, methods, and materials are publicly disclosed. This interpretation is consistent with prior research that examined researchers working in a handful of science fields at American universities. It appears the adverse effect of industry sponsorship on disclosure of academic research is not country specific or university specific, although more research is clearly needed to understand how country-level and institution-level characteristics influence the relationship between sponsorship and disclosure. 
Figure 1: Percentage of higher education and government R\&D financed by industry 1981, 1995, 2007

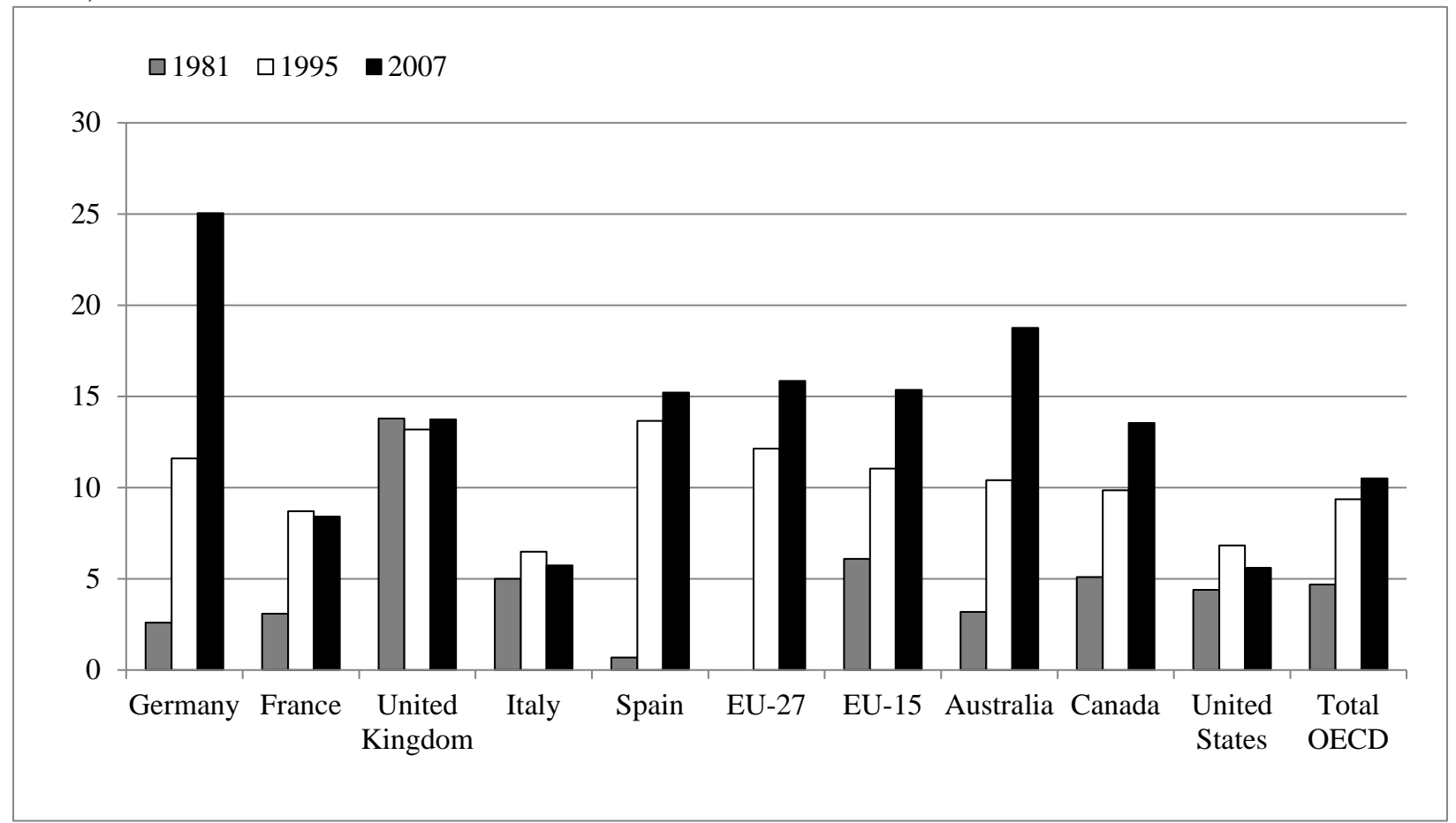

Source: OECD, Main Science and Technology Indicators 2010

The challenge facing policymakers is to gauge the impact of disclosure restrictions on the quantity, quality, and evolution of academic research to better understand how these restrictions may ultimately influence innovation and economic growth. This is a significant challenge and our study only lays the groundwork for more research. Before policy recommendations can be made numerous follow-on questions must be answered. For instance: What is the quantity and nature of information delayed or withheld? How do these disclosure restrictions affect the access costs, fidelity, and use of ideas that compose the stock of public scientific and technical knowledge? How important is the information delayed or withheld for private returns? What are the net social costs or benefits of disclosure restrictions? At this stage of the research, policymakers should at least be aware that academic researchers are accepting disclosure restrictions in exchange for financial support by industrial sponsors. If, as David (1994) argued, sponsorship relationships played an important role in the emergence of open science, it is only 
logical that sponsorship relationships are influential enough to undermine open science norms and practices.

\section{References}

Audretsch, D.B., W. Bönte, and S. Krabel (2010), Why do scientists in public research institutions cooperate with private firms?, DRUID Working Paper No. 10-27, Copenhagen.

Blumenthal, D., E.G. Campbell, M.S. Anderson, N. Causino, and K. Seashore-Louis (1997), Withholding research results in academic life science, Journal of the American Medical Association 277(15), 1224-1228.

Blumenthal, D., E.G. Campbell, N. Causino, and K. Seashore-Louis (1996), Participation of lifescience faculty in research relationships with industry, The New England Journal of Medicine 335(23), 1734-1739.

Blumenthal, D., E.G. Campbell, M. Gokhale, R. Yucel, B. Clarridge, S. Hilgartner, and N.A. Holtzman (2006), Data withholding in genetics and other life sciences: Prevalences and practices, Academic Medicine 81(2), 137-145.

Blumenthal, D., N. Causino, E.G. Campbell, and K. Seashore-Louis (1996), Relationships between academic institutions and industry in the life sciences - an industry survey, The New England Journal of Medicine 334(6), 368-373.

Blumenthal, D., M. Gluck, K. Seashore-Louis, M.A. Stoto, and D. Wise (1986), Universityindustry research relationships in biotechnology: Implications for the university, Science Magazine 232(4756), 1361-1366. 
Campbell, E.G., J.S. Weissman, N. Causino, and D. Blumenthal (2000), Data withholding in academic medicine: characteristics of faculty denied access to research results and biomaterials, Research Policy 29(2) 303-312.

Dasgupta, P., and P.A. David (1994), Toward a new economics of science, Research Policy 23(5), 487-521.

David, P.A. (2004), Understanding the emergence of 'open science' institutions: functionalist economics in historical context, Industrial and Corporate Change 13(4), 571-589.

Cohen, W.M., R. Florida, L. Randazzese, and J. Walsh (1998), Industry and the academy: Uneasy partners in the cause of technical advance, in: R.G. Noll (ed.), Challenges to Research Universities, Washington, DC: Brookings Institution Press.

Gans, J.A., F.E. Murray, and S. Stern (2010), Contracting over disclosure of scientific knowledge: Intellectual property and academic freedom, mimeo, Cambridge.

Geuna, A. (2001), The changing rationale for European university research funding: Are there negative unintended consequences?, Journal of Economic Issues 35(3), 607-630.

Goddard, J.G., and M. Isabelle (2006), Managing intellectual assets within knowledge-based partnerships: Insights from a survey of public laboratories collaborating with industry, IMRT Working paper 2006/03, downloaded on 12/05/2010 from http://papers.ssrn.com/sol3/papers.cfm?abstract_id=1340209.

Haeussler, C. (2011), Information-sharing in academia and the industry: A comparative study, Research Policy 40(1), 105-122.

Hong, W., and J.P. Walsh (2009), For money or glory?: Commercialization, competition and secrecy in the entrepreneurial university, Sociological Quarterly 50(1), 145-171. 
Merton, R.K. (1973), The sociology of science: theoretical and empirical investigations, Chicago: University of Chicago Press.,

Miranda, A., and S. Rabe-Hesketh (2006), Maximum likelihood estimation of endogenous switching and sample selection models for binary, ordinal, and count variables, The Stata Journal 6(3), 285-308.

Mukherjee, A., and S. Stern (2009), Disclosure or secrecy? The dynamics of open science, International Journal of Industrial Organization 27(3), 449-462.

Murray, F., P. Aghion, M. Dewatripont, J. Kolev, and S. Stern, (2009), Of mice and academics: Examining the effect of openness on innovation, NBER Working paper No. 14819, Cambridge.

Stephan, P.E. (1996), The economics of science, Journal of Economic Literature 34(3), 11991235.

Thursby, J.G., and M.C. Thursby (2007), University licensing, Oxford Review of Economic Policy 23(4), 620-639.

Walsh. J.P., W.M. Cohen, and C. Cho (2007), Where excludability matters: Material versus intellectual property in academic biomedical research, Research Policy 36, 1184-1203.

Wooldridge, J.M. (2002), Econometric analysis of cross section and panel data, Cambridge: MIT Press. 